International Business Management 13 (2): 49-62, 2019

ISSN: $1993-5250$

(C) Medwell Journals, 2019

\title{
Investigating the Influence of Strategic Planning on University Operational Performance: The Mediating Role of Organizational Commitment in UAE
}

\author{
${ }^{1}$ Bandar Abdulla F.H. Alharthi, ${ }^{1}$ Gamal S.A. Khalifa, ${ }^{1}$ Ali Ameen, \\ ${ }^{2}$ Osama Isaac and ${ }^{1} \mathrm{~A}$ hmed Hamoud Al-Shibami \\ ${ }^{1}$ Faculty of Business and Accountancy, Lincoln University College (LUC), Selangor, Malaysia \\ ${ }^{2}$ Faculty of Tourism and Hotels, Fayoum University, Fayoum, Egypt
}

\begin{abstract}
This study purpose is to identify the relationship among Strategic Planning (SP), Organizational Commitment (OC) and university operational Performance (PERF). This relationship indicates the identifications of UAE universities. A quantitative research approach has followed in this study and survey-based questionnaire was appeared to collect data from universities academic staffs. All together 500 questionnaires was distributed among the staffs and 309 valid questionnaires were collected. All study hypothesis were supported. SL is positively predicted OC and UOP. In addition OC mediates the relationship between SL and UOP. Managerial and theoretical implications are introduced.
\end{abstract}

Key words: Strategic planning, organizational commitment, university performance, UAE, survey-based, predicted $O C$ and UOP

\section{INTRODUCTION}

University operational performance is an important point of sometimes essential to set up different services of maintain steadiness and competition of any given situation (Agwa et al., 2018a, b; Hussein et al., 2013; Tangen, 2003). The economic aspect of operational performance concentrates on the importance of the external market criteria of the organization such as competitive advantage while the organizational aspect concerns sociological and behavioral attitudes and their reaction with the organization's environment (Abd-Elaziz et al., 2015; Jiang et al., 2006; Khalifa and Hewedi, 2016). Jiang et al. (2006) have reported that by creating some kind of compatibility and harmonization between the resources, knowledge and vision and its positive response to environmental changes that would lead to acquiring a competitive advantage in the market (Abou-Shouk and Khalifa, 2017; Khalifa and Abou-Shouk, 2014; Khalifa and Fawzy, 2017). Additionally, operational performance indicates the performance of any organization includes a number of multi-faceted appropriations between six criteria effectiveness, efficiency, quality, productivity, innovation and profitability (Al-Shamsi et al., 2018; Khalefa, 2015; Mohamud et al., 2017; Rolstadas, 1998). This study has articulated university operational performance as a dependent construct in the model that makes an essential point of others influences. It is comprised the university overall service and administrative related operational performance.

Moreover, the strategy as practice relies mainly on managers who develop, implement and discuss internal and external that effect on organizational outcomes (Bryson, 2018; Isaac et al., 2016; Khalifa and Mewad, 2017). The theoretical underpinning and the literature related to strategy and planning combines the way of ding plane for the future. In addition, Drucker and Rousham, (1974) have defined strategic planning as the planning for an organization's future that includes setting major overall objectives the determination of basic approaches to be used in pursuing these objectives and the means to be used in obtaining the necessary resources to be employed (Bryson, 2018).

Adair has acknowledged that strategic planning depends on defining the organization's key priorities over the long term. As a result of strategic planning, the organization produces many strategies to be carried out. Murray and Montanari (1986) affirmed that the strategy is the basic approach to achieve the organization's overall objectives (Babafemi, 2015). This study, strategic planning has addressed as an independent variable that influence on university operational performance directly and indirectly through organizational commitment. There

Corresponding Author: Gamal S.A. Khalifa, Faculty of Hospitality and Tourism, Lincoln University College (LUC), Selangor, Malaysia 
is little studies has been considered in the literature in specific relationship of strategic planning and university and organizational commitment. In this this study, this relationship have clarified in the context of universities related study. Organizational commitment is one of the most important concepts used in organizational behavior and human resource management (Basu et al., 2002; Mohamed et al., 2019). Although, it is regarded as one construct which has divided into three different aspects emotional, continuity and normative commitment (Alkhateri et al., 2018; Meyer and Allen, 1984).

According to, Delpechitre et al. (2018) the emotional commitment is an employee's emotional attachment to identify with involvement in the organization. The continuing commitment is the commitment based on the costs that employee's associate with leaving the organization, the normative obligation of employee's feelings of obligation to remain with the organization (Dhar, 2016; Garg and Dhar, 2014). The most important feature of commitment in the working environment is mediation that performed as intermediaries in institutions (Van der $\mathrm{Bij}$ et al., 2003). Organizational commitment have addressed in this study as a mediating role of strategic planning and university operational performance. This indirect relationship to achieve university operational performance is first attempt to investigate the connection, according to, theoretical evidences and author's knowledge. This study aims to investigate the relationship between SP and UOP via. OC.

\section{Literature review}

Strategic planning: The concept of strategic planning and management began to be used in the profit-based organizations, since, in the 1950's (Miller and Cardinal, 1994; Wolf and Floyd, 2017). All the tools and models of strategic management currently have used both private and public organizations (Bryson, 2010; Poister, 2010). The use of it generated from the tension between resource shortage and demands for improving services performance increased aspirations of external stakeholders to service accountability and greater commitment of public agency practitioners to better management (Poister, Pitts and Hamilton Edwards, 2010; Berry, 2016). Furthermore, the strategic planning has been shown the result of major changes in science, technology and many aspects of social, economic, financial and education (Bryson, 2010; Cardinal et al., 2015).

Meanwhile, the world has become a super-globalized and hyper connected with new strategic planning where any development anywhere could be widely echoed elsewhere (Bryson, 2018; Haines, 2016). Consequently, the strategic management promotes internal and external communication and works to define a strategic agenda through the participation of stakeholders in shared values (Joyce, 2016; Poister, 2010; Poister et al., 2010). Universities have effectively adopted and shown better performance compared to other organizations that have not embraced strategic planning (Arasa and K'Obonyo, 2012; Ayers, 2015; Yousaf and Majid, 2016). However, strategic planning influence on university operational performance in order to make long term plan for the organization and increase organizational performance with the success. This relationship acts as direct and mediating influence on operational performance through organizational commitment. Accordingly to best of researchers knowledge the indirect influence on university operational performance is the first attempt to stand this relationship. A large number of studies have confirmed that companies which have implemented strategic planning have significantly improved their performance (Cardinal et al., 2015; McAfee and Champagne, 1993; Miller, 2016; Miller and Cardinal, 1994; Ouakouak and Ouedraogo, 2013; Wilden et al., 2013):

$\mathrm{H}_{1}$ : strategic planning positively influence university operational performance

$\mathrm{H}_{2}$ : strategic planning positively influence on organizational commitment

Organizational commitment: Organizational commitment is traditionally defined as a strong belief in and acceptance of the organization's goals and values a willingness to exert considerable effort on behalf of the organization and a definite desire to maintain organizational membership" (Basu et al., 2002; Roast and Silva-Rojas, 2007). Meyer et al. (1989) have believed that regulatory commitment is an important part of the psychological condition of employees and the attitudes they are generalizing towards. Others define the organizational commitment as the extent and degree to which employees feel connected and belong to the organization (Basu et al., 2002; Joo and Shim, 2010; Mosadeghrad and Ferdosi, 2013). Accordingly, Bryson, (2018) emphasized that the organization that suffers from a lack of commitment, especially, at the senior management level. Albacete-Saez et al. (2011) stated that the implementation of the organizational strategic priorities depends on the commitment of the top management. It was found that the employee and his contributions have an active role in the organizational strategic process which leads to a greater understanding of the strategy among the staff and a greater commitment 


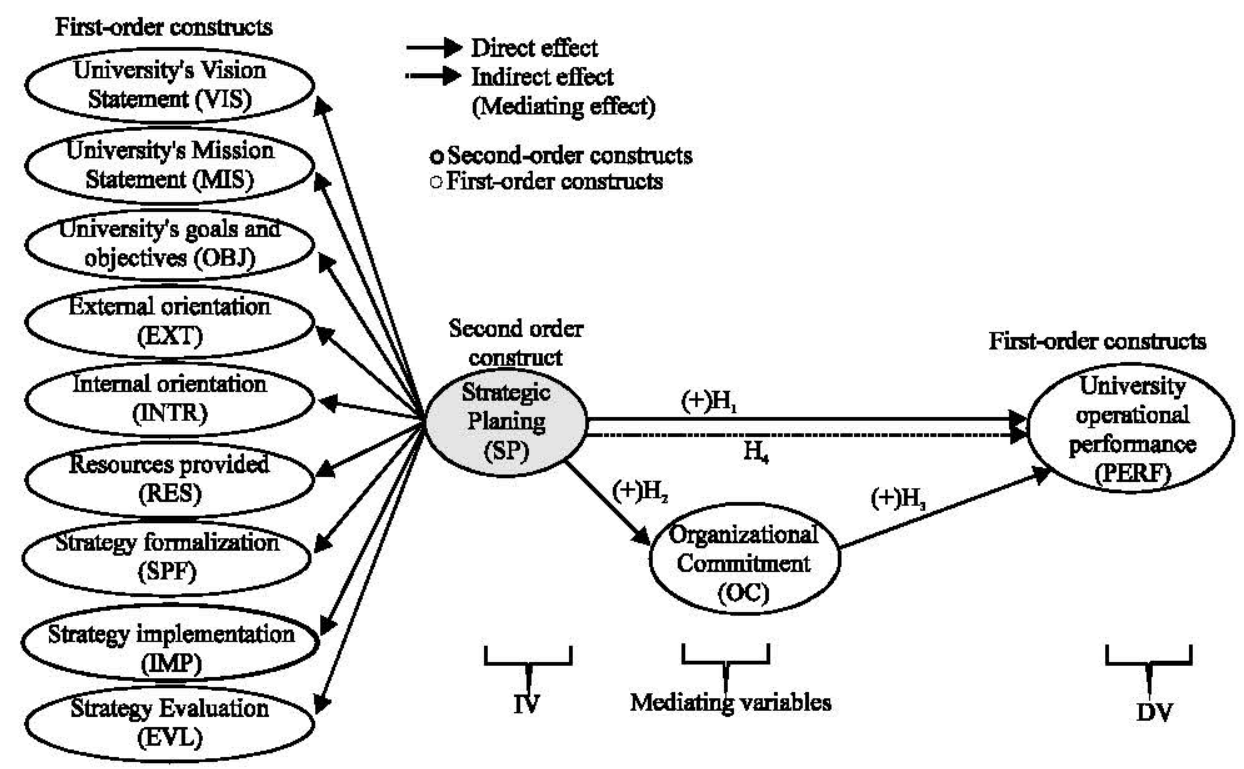

Fig. 1: The conceptual framework

to the strategy (Alfalla-Luque et al., 2015; Tonnessen and Gjefsen, 1999). A general agreement on the organization's strategy emerges from the employee's participation (Kohtamaki et al., 2012; Siren and Kohtamaki, 2016; Siren et al., 2012; Tonnessen and Gjefsen, 1999) which in turn increases the employee's commitment and motivation and leads to shortening the time required to fulfil the strategy (Alkhateri et al., 2018; Nusari et al., 2018; Siren and Kohtamaki, 2016; Tonnessen and Gjefsen, 1999) (Fig. 1).

However, employee commitment has addressed in this study as an important role for mediation effect and direct influence. Strategic planning influences on organizational commitment and organizational commitment influence on university operational performance. Organizational performance influences on operational performance (Meyer et al., 1989; Mohamed et al., 2018) and little studies has been investigated in order to relates the mediation effect of organizational commitment that indicates as a first attempt of standing relationship (Alkhateri et al., 2018). Thus, the level of employee commitment is to welcome, understand and support the company's objectives. Unlike those who feel strongly committed, employees that are identified within the organization's goals and do their jobs better (Ackfeldt and Malhotra, 2013). It is therefore possible to develop long-term relationships with committed and enthusiastic employees (Mohamed et al., 2018; Gounaris, 2005). Therefore, based on the foregoing, the present study provides the following hypothesis:
$\mathrm{H}_{3}$ : organizational commitment positively influence on university operational performance

$\mathrm{H}_{4}$ : organizational commitment mediates between strategic planning and university operational performance

University operational performance: Operational performance is an important issue in learning and management fields (Almatrooshi et al., 2016) that extract the outcomes of the organization. It is through participation and employee commitment that will provide a good feedback from the employees (Mowday et al., 1997). It is necessary to achieve the best performance among employees which will be achieved only by providing a good working environment and selection process, continuous planning, training and development and physical and moral motivation either through financial rewards or through promotion which was the core point of my research (Alkhateri et al., 2018; Badran and Khalifa, 2016; Bhatti et al., 2014; Khalaf et al., 2016). The employee usually practices three behaviors that improve operational performance (Almatrooshi et al., 2016; Bhatti et al., 2014; Waddock and Bodwell, 2017) such as employee's permanent defenses toward the organization, employee's strong desire to be a member of the organization and loyalty to it despite the temptations of employment elsewhere. Besides, employee's attempts to exert more time, effort and initiative to ensure the proper workflow which leads to the organization's success (Al-Shamsi et al., 2018; Alkhateri et al., 2018; Badran and Khalifa, 2016; Baumruk, 2006; Qoura and Khalifa, 2016). 
On the other side, it is an indicator of the organizational recession period that usually grows in parallel with the increased overall performance (Almatrooshi et al., 2016; Khalifa et al., 2016) that capitalize in social dimensions such as employees, the community and the environment (Schwartz, 2017). However, university operational performance acts in the study as a dependent variable in order to place to get outcomes of the strategic plan and commitment. Operational performance has been discussed in the literature in several studies more specifically university operational performance has not investigated in the literature. This construct is made the model as a unique model for new and lucrative investigation for the UAE universities. In this regard, many of the previous studies were held in Western countries but what distinguishes this research is the fact that it is verifying the existence of these links and bonds in the United Arab Emirates as it is considered outside the western frame. As a result, the research outcomes are verifing the excitance of these potential mediation variables. It is obvious that $O C$ plays a critical role in enhancing university operational performance.

\section{MATERIALS AND METHODS}

Research design: Research design specifies the way of conducting study including research approaches in the field. With the positivism and objective universal, indicates the ontology and epistemological paradigm in the research. A quantitative research approach follows data collection and analysis may be inferred from the development of the argument in line with the positivist and objectivist paradigms (Marshall and Rossman, 1999). This research has appeared with survey-based questionnaire to collect data from the UAE universities academic staffs and get feedback instantly. Universities staffs are frequently answered the questionnaire in order to follows the questionnaire or interview procedures to collect information regarding the problem and context of the study field.

For testing the hypothesis, a survey questionnaire consists of four parts with questions focused on the flowing contents demographic profile, strategic planning (Albadry, 2016; Galbreath, 2010) organizational commitment (Albadry, 2016) and university operational performance (Garcia-Morales et al., 2012). Brynard and Hanekom (1997) argue that quantitative methods tend to be more suitable when the need to assign figures and direct an investigation towards the realization of a universal truth. In this concept to determine the reliability and validity, hypothesis testing of the measurement variables quantitative methods can be used ( $Z$ ikmund, 2003). Information about respondent's beliefs, motives and attitudes provides by an effective survey design in the study field in the case of research, measure the perceptions of organization employees.

Research sampling and data collection: This reserach was used a non-probability random sampling for the UAE universitis The data was colleted into four steps; first steps have taken two months to get 100 valid questionnares form the academic staffs. Accordingly, four steps together collected 570 valid questionnares after distriduting 650 questionnares. A respondent was asked to give their answer which is measured on a 5-point Likert scale ranging from 1-(Strongly Disagree) to 5-(Strongly Agree). At first, prepared questionnare sample was showd to the authories to get permission. The authory reviewd the questionnare and give us feedback to collect data. For the analysis, this study was used PLS (Pertial Least Squire) analytical procedues in oder to find factor loading, path and model fit.

\section{RESULTS AND DISCUSSION}

Descriptive analysis: The researcher distributed 500 questioners to the Academic staff in UAE's educational institutions, the valid questionnaires were received by the researcher are 309 questionnaires by responding rate is $61.8 \%$. The responding sample $(\mathrm{n}=309)$ consisted of $62.5 \%$ male and $37.5 \%$ female employees. Most of the participants were aged between 30-39 years this accounted for $41.7 \%$ of the responses followed by the age range of $<30$ years at $30.7 \%$ of total responses. With regards to the academic positions of selected participants, 54.4 of participants were assistant professors, $26.5 \%$ were associate professors and all other categories had nearly the same number of participants. Close to $25.3 \%$ of the respondent's working experience were $<5$ years; followed by the experience range of $11-15$ years at $23.6 \%$ of total responses. A total of 71 , accounting for $22.98 \%$ of the respondents were workers in public universities whilst the remaining worked in private institutions (Table 1).

Measurement model assessment: Schumacker and Lomax (2004) and Hair et al. (2010) indicate that the two steps assessment procedure which includes measurement model and structural model has an advantage over the one step assessment procedure. According to, Hair et al. (2017) measurement model specifies how each construct is measured, while structural model specifies how the variables are related to each other in the structural model. The main reasons for choosing PLS as a statistical 
Int. Business Manage., 13 (2): 49-62, 2019

Table 1:Summary of demographic profile of respondents

\begin{tabular}{lrc}
\hline Variables & Frequency & Valid (\%) \\
Gender & 193 & \\
Male & 116 & 62.5 \\
Female & & 37.5 \\
Age & 95 & \\
Less than 30 & 129 & 30.7 \\
$30-39$ & 66 & 41.7 \\
$40-49$ & 15 & 21.4 \\
50-59 & 4 & 4.9 \\
60 and above & & 1.3 \\
Experience & 78 & \\
Less than 5 years & 56 & 25.3 \\
5-10 & 73 & 18.1 \\
11-15 & 54 & 23.6 \\
16-20 & 48 & 17.5 \\
More than 20 & & 15.5 \\
Academic position & 26 & \\
Teaching assistant & 82 & 8.4 \\
Lecturer & 168 & 26.5 \\
Assistant Professor & 20 & 54.4 \\
Associate Professor & 13 & 6.5 \\
Professor & & 4.2 \\
University & 71 & \\
Public & 238 & 22.98 \\
Private & 309 & 77.02 \\
Total & & \\
\hline
\end{tabular}

method for this study that for both measurement and structural model PLS offer simultaneous analysis which leads to more accurate estimates (Barclay et al., 1995) (Table 2).

The assessment of measurement model was done through construct reliability as well as validity (including convergent and discriminant validity). For Construct reliability, this study tested the individual Cronbach's alpha coefficients to measure the reliability of each of the core variables in the measurement model. The results indicate that all the individual Cronbach's alpha coefficients ranging from $0.857-0.977$ were higher than the suggested value of 0.7 (Kannana and Tan, 2005; Nunnally and Bernstein, 1994). Additionally, for testing construct reliability all the Composite Reliability (CR) values ranging from $0.903-0.978$ were higher than 0.7 (Linn and Joreskog, 1974; Kline, 2010; Gefen et al., 2000) which adequately indicates that construct reliability is fulfilled as shown in Table 2. Therefore, the achieved Cronbach's Alpha and CR for all constructs were considered to be sufficiently error-free.

Factor loading was used to test indicator reliability. High loadings on a construct indicate that the associated indicators seem to have much in common which is captured by the construct (Hair et al., 2017). Factor loadings $>0.50$ were considered to be very significant (Hair et al., 2010). The loadings for all items exceeded the recommended value of 0.5 as shown in Table 2 . The loading for all items in the model has, therefore, fulfilled all the requirements.
Table 2: Mean, standard deviation, loading, cronbach's Alpha, CR and

\begin{tabular}{lllll} 
AVE & & & & \\
\hline & Loading & $\alpha$ & CR & AVE
\end{tabular}

$\begin{array}{lllllll}\text { Constructs/Items } & (>0.5) & \text { M } & \text { SD } & (>0.7) & (>0.7) & (>0.5) \\ \text { Strategic planning } & & & & & & \end{array}$

(SL)

$\begin{array}{lllllll}\text { EVL1 } & 0.851 & 4.22 & 1.377 & 0.977 & 0.978 & 0.674\end{array}$

EVL2 $\quad 0.748$

EVL3 0.893

EVL4 0.919

EXT1 0.815

EXT2 0.891

EXT3 0.887

EXT4 0.812

EXT5 0.801

IMPL1 $\quad 0.840$

IMPL2 $\quad 0.881$

IMPL3 $\quad 0.862$

IMPLA $\quad 0.841$

IMPL5 $\quad 0.776$

INTR1 0.881

INTR2 0.902

INTR4 $\quad 0.881$

$\begin{array}{ll}\text { INTR5 } & 0.817\end{array}$

INTR6 $\quad 0.876$

MISS1 $\quad 0.767$

MISS2 $\quad 0.855$

MISS3 $\quad 0.860$

MISS4 $\quad 0.860$

OBJ1 $\quad 0.877$

OBJ2 $\quad 0.895$

OBJ3 0.909

RES1 0.856

RES2 0.905

RES3 0.902

RES4 0.857

RES5 0.880

SP1 $\quad 0.811$

SP2 0.866

SP3 $\quad 0.862$

SP4 0.808

VIS1 0.870

VIS2 0.879

VIS3 $\quad 0.874$

VIS4 $\quad 0.760$

Organization Commitment (OC)

$\begin{array}{lllllll}\text { OC1 } & 0.836 & 4.14 & 1.606 & 0.934 & 0.950 & 0.793\end{array}$

OC2 0.914

OC3 0.945

OC4 0.932

OC5 0.820

University Operational Performance (PERF)

$\begin{array}{lllllll}\text { PERF1 } & 0.679 & 4.33 & 1.594 & 0.857 & 0.903 & 0.701\end{array}$

PERF2 $\quad 0.780$

PERF3 0.870

PERF4 0.878

PERF5 $\quad 0.864$

PERF6 $\quad 0.784$

$\mathrm{M}=$ Mean; $\mathrm{SD}=$ Standard Deviation, $\alpha=$ Cronbach's alpha; $\mathrm{CR}=$ Composite Reliability, AVE = Average Variance Extracted; The measurement used is seven-point scale ranging from 1 (strongly disagree) to 7 (strongly agree); All the factor loadings of the individual items are statistically significant $(\mathrm{p}<0.01)$

For testing convergent validity (the extent to which a measure correlates positively with alternative measures of the same construct, this study used the Average Variance Extracted (AVE) and it indicated that all AVE 
values were higher than the suggested value of 0.50 (Hair et al., 2010) ranging from 0.674-0.793. The convergent validity for all constructs has been successfully fulfilled and adequate convergent validity exhibited as Table 2 shows.

The discriminant validity (the degree to which items differentiate among constructs or measure distinct concepts) of the measurement model was checked using three criteria, namely cross-loadings, Fornell-Larcker and the HeteroTrait-MonoTrait ratio (HTMT). According to Hair et al. (2017) the cross-loadings are typically the first approach to assess discriminant validity of the indicators. As shown in Table 3 the cross loading criterion fulfills the requirements because the indicators outer loadings on a construct were higher than all its cross-loadings with other constructs (bold values).

The results of discriminant validity by using the Fornell-Larcker criterion is shown in Table 4 where the square root of the AVEs on the diagonals as represented by the bolded values are higher than the correlations between constructs (corresponding row and column values). This indicates that the constructs are strongly related to their respective indicators compared to other constructs of the model (Fornell and Larcker, 1981; Chin, 1998), thus, suggesting a good discriminant validity (Hair et al., 2017). In addition, the correlation between exogenous constructs is $<0.85$ (Awang, 2014). Hence, the discriminant validity of all constructs is fulfilled.

There has been some criticism of the Fornell-Larcker criterion, Henseler, Ringle and Sarstedt (2016) mentioned that it does not accurately reveal the lack of discriminant validity in common research situations. They have proposed an alternative technique which is the HeteroTrait-MonoTrait ratio (HTMT) of correlations based on the multitrait-multimethod matrix. This study assesses discriminant validity through HTMT. While the discriminant validity has a problem when the HTMT value is greater than HTMT0.90 value of 0.90 (Gold et al., 2001) or the HTMT0.85 value of 0.85 (Kline, 2010) all values as Table 5 shows were lower than the recommended value of 0.85 indicating that discriminant validity has been ascertained.

Structural model assessment: Hair et al. (2017) suggested assessing the structural model by looking at the beta $(\beta), \mathrm{R}^{2}$ and the corresponding t-values via. a bootstrapping procedure with a resample of 5,000 . Moreover, they recommend reporting the effect sizes $\left(\mathrm{f}^{2}\right)$ as well as the predictive relevance $\left(Q^{2}\right)$. As (Sullivan and Feinn, 2012) argue that, the p-value determine whether the effect exists but it does not reveal the size of the effect.
Table 3: Results of discriminant validity by the cross loading

\begin{tabular}{|c|c|c|c|}
\hline Variables & INN & PERF & SP \\
\hline EVL1 & 0.424 & 0.589 & 0.851 \\
\hline EVL2 & 0.536 & 0.597 & 0.748 \\
\hline EVL3 & 0.486 & 0.648 & 0.893 \\
\hline EVL4 & 0.528 & 0.638 & 0.919 \\
\hline EXT1 & 0.494 & 0.538 & 0.815 \\
\hline $\mathrm{EXT} 2$ & 0.537 & 0.537 & 0.891 \\
\hline EXT3 & 0.621 & 0.613 & 0.887 \\
\hline EXT4 & 0.625 & 0.545 & 0.812 \\
\hline EXT5 & 0.510 & 0.471 & 0.801 \\
\hline IMPL1 & 0.609 & 0.707 & 0.840 \\
\hline IMPL2 & 0.549 & 0.716 & 0.881 \\
\hline IMPL3 & 0.548 & 0.652 & 0.862 \\
\hline IMPLA & 0.580 & 0.670 & 0.841 \\
\hline IMPL5 & 0.494 & 0.578 & 0.776 \\
\hline INTR1 & 0.541 & 0.634 & 0.881 \\
\hline INTR2 & 0.577 & 0.608 & 0.902 \\
\hline INTR4 & 0.563 & 0.606 & 0.881 \\
\hline INTR5 & 0.514 & 0.504 & 0.817 \\
\hline INTR6 & 0.440 & 0.548 & 0.876 \\
\hline MIS1 & 0.438 & 0.415 & 0.767 \\
\hline MIS2 & 0.487 & 0.483 & 0.855 \\
\hline MIS3 & 0.546 & 0.565 & 0.860 \\
\hline MIS4 & 0.635 & 0.600 & 0.860 \\
\hline RES1 & 0.587 & 0.595 & 0.856 \\
\hline RES2 & 0.656 & 0.571 & 0.905 \\
\hline RES3 & 0.665 & 0.489 & 0.902 \\
\hline RES4 & 0.578 & 0.646 & 0.857 \\
\hline RES5 & 0.568 & 0.659 & 0.880 \\
\hline OBJ1 & 0.529 & 0.540 & 0.877 \\
\hline OBJ2 & 0.408 & 0.428 & 0.895 \\
\hline OBJ3 & 0.394 & 0.443 & 0.909 \\
\hline SP1 & 0.508 & 0.479 & 0.811 \\
\hline SP2 & 0.443 & 0.443 & 0.866 \\
\hline SP3 & 0.486 & 0.454 & 0.862 \\
\hline SP4 & 0.528 & 0.514 & 0.808 \\
\hline VIS1 & 0.462 & 0.389 & 0.870 \\
\hline VIS2 & 0.474 & 0.366 & 0.879 \\
\hline VIS3 & 0.471 & 0.428 & 0.874 \\
\hline VIS4 & 0.480 & 0.417 & 0.760 \\
\hline OC1 & 0.836 & 0.604 & 0.675 \\
\hline $\mathrm{OC} 2$ & 0.914 & 0.628 & 0.634 \\
\hline OC3 & 0.945 & 0.644 & 0.658 \\
\hline $\mathrm{OC} 4$ & 0.932 & 0.670 & 0.686 \\
\hline OC5 & 0.820 & 0.531 & 0.616 \\
\hline PERF1 & 0.419 & 0.679 & 0.480 \\
\hline PERF2 & 0.534 & 0.780 & 0.611 \\
\hline PERF3 & 0.621 & 0.870 & 0.745 \\
\hline PERF4 & 0.590 & 0.878 & 0.721 \\
\hline PERF5 & 0.575 & 0.864 & 0.725 \\
\hline PERF6 & 0.539 & 0.784 & 0.656 \\
\hline
\end{tabular}

SP: Strategic Planning; OC: Organizational Commitment; IMPL: Strategy Implementation; SPF: Strategy Formalization; INTR: Internal Orientation; EXT: External orientation; VIS: University Vision; MIS: University Mission; RES: Resources Provided; OBJ: Goals and Objectives; EVL: strategic planning Evaluation; PERF: University operational performance

\begin{tabular}{lccr}
\multicolumn{4}{l}{ Table 4: Results of discriminant validity by Fornell-Larcker criterion } \\
\hline Variables & OC & PERF & SP \\
\hline OC & 0.891 & & \\
PERF & 0.693 & 0.812 & \\
SP & 0.635 & 0.617 & 0.880 \\
\hline
\end{tabular}

Diagonals represent the square root of the average variance extracted while the other entries represent the correlations; SP: Strategic Planning; OC: Organizational Commitment; PERF: University operational performance

Hypothesis tests: The structural model assessment as shown in Fig. 2 and Table 6 provides the indication of the 


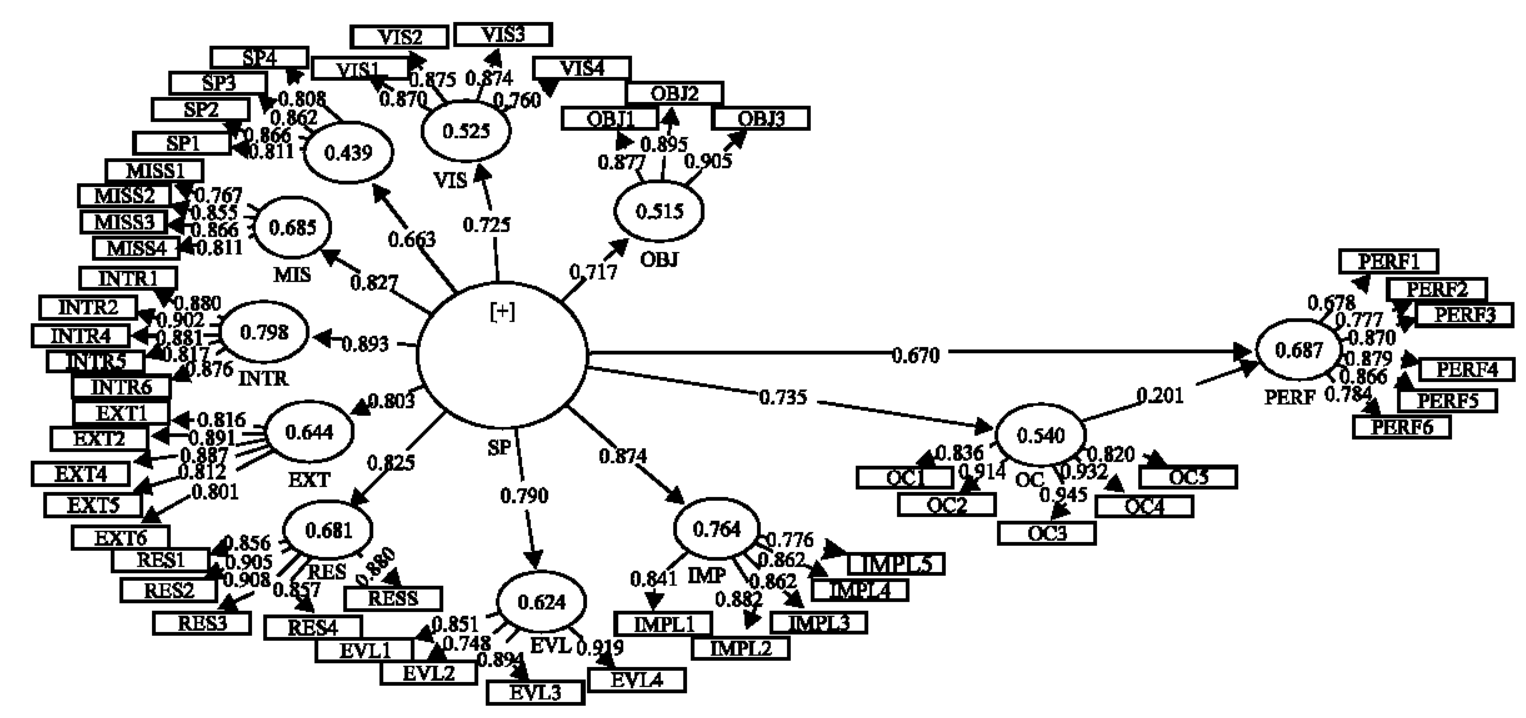

Fig. 2: PLS algorithm results

\begin{tabular}{lcc}
\multicolumn{2}{l}{ Table 5: Results of discriminant validity by HTMT } & \\
\hline Variables & OC & PERF \\
\hline OC & & \\
PERF & 0.748 & SP \\
SP & 0.764 & 0.864 \\
\hline
\end{tabular}

Table 6: Structural path analysis result

\begin{tabular}{|c|c|c|c|c|c|c|c|c|c|c|}
\hline Hypothesis & Relationship & Std Beta & SE & $\mathrm{t}$-values & $p$-values & Decision & $\mathrm{R}^{2}$ & $\mathrm{f}^{2}$ & $\mathrm{Q}^{2}$ & $\mathrm{VIF}$ \\
\hline $\mathrm{H}_{1}$ & SP->PERF & 0.670 & 0.665 & 10.210 & 0.000 & Supported & 0.687 & 0.657 & 0.421 & 2.175 \\
\hline $\mathrm{H}_{2}$ & $\mathrm{SP}->\mathrm{OC}$ & 0.735 & 0.734 & 13.036 & 0.000 & Supported & 0.540 & 1.157 & 0.399 & 1.000 \\
\hline $\mathrm{H}_{3}$ & OC->PERF & 0.201 & 0.207 & 3.021 & 0.003 & Supported & 0.687 & 0.059 & & 2.175 \\
\hline
\end{tabular}

SP: Strategic Planning; OC: Organizational commitment; PERF: University operational performance

hypothesis tests with 3 out of the 3 hypothesis are supported. SL significantly predicts OUP and OC. Hence, $\mathrm{H}_{1}$ and $\mathrm{H}_{2}$ are accepted with $(\beta=0.670, \tau=10.210$, $\mathrm{p}<0.001)$ and $(\beta=0.735, \tau=13.036, \mathrm{p}<0.001)$, respectively. In addition $\mathrm{OC}$ significantly predicts OUP. Hence, $\mathrm{H}_{3}$, is accepted with $(\beta=0.201, \tau=3.021, p<0.01)$. Note that, the standardized path coefficient indicates the strengths of the relationship between exogenous and endogenous constructs, so, the direct effects of SP on OUP are much stronger than the influence of other variables.

SP and $\mathrm{OC}$ are explaining $68.7 \%$ of the variance in OUP. The $\mathrm{R}^{2}$ values achieved an acceptable level of explanatory power as recommended by Cohen (1988) and Chin (1998a, b) indicating a substantial model. This study also assessed effect sizes $\left(\mathrm{f}^{2}\right)$. Effect size $\mathrm{f}^{2}$ determines whether an exogenous latent construct has a substantial, moderate or weak impact on an endogenous latent construct (Gefen and Rigdon, 2011). Hair et al. (2017) recommend to test the change in the $\mathrm{R}^{2}$ value. Cohen (1988) suggested a guideline measure the magnitude of the $\mathrm{f}^{2}$ which is 0.35 (large effects), 0.15 (medium effects) and 0.02 (small effects). The result of $\mathrm{f}^{2}$ as Table 6 shows that one relationship with large effect sizes and two relationships with medium effect size.

Further, by using the blindfolding procedure this study examined the power of research proposed model regarding the predictive relevance. As recommended by Hair et al. (2017) the blindfolding procedure should use only on the endogenous constructs with a reflective measurement. If the value of $\mathrm{Q}^{2}$ is $>0$ then the predictive relevance of the proposed model exists for a certain endogenous construct (Fornell and Cha, 1994; Hair et al., 2017). As Table 6 shows that all the values of $Q^{2}>0$ indicate that there is an adequate predictive relevance for the proposed model. For the $\mathrm{Q}^{2}$ values, Hair et al. (2017) suggested values of 0.35 (large), 0.15 (medium) and 0.02 (small) as a relative measure of predictive relevance and the result of this study shows that the exogenous have two large predictive relevance.

An issue of the multicollinearity could exist in any study which is not desirable it means that the variance 
Int. Business Manage., 13 (2): 49-62, 2019

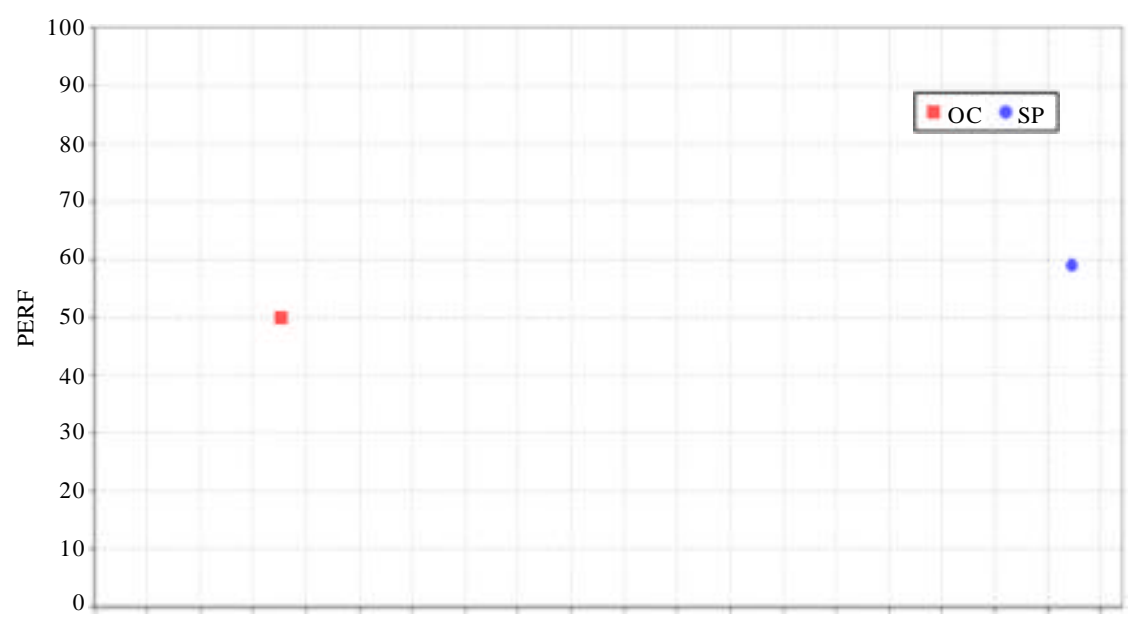

Total effect

Fig. 3: IPMA (Priority Map) for employee performance

\begin{tabular}{|c|c|c|c|c|c|c|}
\hline$\underline{\mathrm{H}}$ & Constructs & B-value & $\mathrm{SE}$ & $\mathrm{t}$-value & P-value & Decision \\
\hline$\underline{\mathrm{H}_{4}}$ & SP $>$ OC $>$ PERF & 0.148 & 0.154 & 2.639 & 0.009 & Supported \\
\hline
\end{tabular}

Strategic Planning; OC: Organizational Commitment; PERF: University operational performance (Preacher and Hayes, 2004, 2008)

exogenous constructs explain in the endogenous construct are overlapping with each other and thus, not each explaining unique variance in the endogenous variable (O'brien, 2007). To measure and assess the degree of multicollinearity, Variance Inflation Factor (VIF) widely used (O'brien, 2007). There is cause for concern when the largest VIF is $>10$ (Bowerman and O'Connell, 1990; Myers, 1990). And according to Hair et al. (2017) a multicollinearity issue exists when the largest VIF is $>5$. Table 6 shows multicollinearity diagnostic through VIF which indicates that there is no evidence of significant multicollinearity among the study exogenous constructs because all VIF values are $<5$ ranging from $1.00-2.175$. It means that the variance of exogenous constructs explains in the endogenous construct are not overlapping with each other.

Indirect hypothesis testing: According to, the bootstrapping's analysis there is a significant indirect impact in the relationship between SP and OUP via. OC with a t-value of 2.639 and $p$-value $<0.01$ as indicated by Preacher and Hayes (2008) that the mediation effect exist when the indirect impact of SP and OUP via. ESA with boot 95\% Cl (LL $=0.066$, UL $=0.277$ ) doesn't straddle a zero in between. Hence, $\mathrm{H}_{4}$ was supported (Table 7).

Importance-Performance Map Analysis (IPMA): This study ran an Importance-Performance Matrix Analysis
Table 8: IPMA for UOP

\begin{tabular}{lcc} 
Latent constructs & $\begin{array}{l}\text { Total effect of the construct } \\
\text { UOP (Importance) }\end{array}$ & $\begin{array}{c}\text { Index values } \\
\text { (Performance) }\end{array}$ \\
\hline OC & 0.176 & 49.967 \\
SP & 0.923 & 59.027 \\
\hline SP: Strategic Planning; OC: Organizational & Commitment; PERF: \\
University operational performance &
\end{tabular}

(IPMA) as a post-hoc procedure in PLS using organizational performance as the outcome construct. The IPMA estimates the total effects represented by the importance of predecessor constructs in shaping the target construct (organizational performance) while their average latent variable scores represent their performance, the computation of the index values (performance scores) was accomplished by rescaling the latent constructs scores to a range of 100 (highest performance) down to 0 (lowest performance) (Hair et al., 2017). According to Ringle and Sarstedt (2016) IPMA enriches the PLS analysis results. Instead of only analyzing the path coefficients (i.e., the importance dimension) it also takes into consideration the average value of the latent constructs and their indicators (i.e., performance dimension). Table 8 shows the findings of importance (total effects) and performance (index values) used for the IPMA.

As shown in Fig. 3, this study plotted the total effects scores and index values in a priority map. It can be observed that SP is a very important factor in determining the UOP due to its relatively higher importance value compared to other constructs in the proposed model. In 
addition, the performance of this significant factor (SP) lagged before the OC. According to Hair et al. (2017) the goal of IPMA is to identify predecessors that have a relatively high importance for the target construct (i.e., those that have a strong total effect) but also a relatively low performance (i.e., low average latent variable scores) the aspects underlying these constructs represent potential areas of improvement that may receive high attention. In sum, in order to improve the UOP, the managerial activities should focus on enhancing the performance of SP.

\section{CONCLUSION}

This study discussion was found, according to, the finding results of the study. The reliability and validity of the instruments are obligatory if we aim to produce meaningful results (Dembo et al., 2015). Therefore, the variable's validity and reliability were greatly acceptable as was mentioned prior in the result. This study connected as the prior investigation between strategic planning and organizational commitment toward university operational performance. Furthermore, the mediation of organizational commitment acts as unique role of investigation. The findings suggested that the strategic planning significant and positively influence on organizational commitment. This relationship indicates that the strategic planning in universities or higher education sector is summarized that comprehensive planning was conspicuously absent (Mintzberg, 2000). Strategic planning sets priorities and decisions from the perspective of standards and functions in order to support stakeholders effectively, efficiently, professionally and responsibly. Thus, SP strengthens the future direction of the organisation (Bergeron et al., 2004; Dibrell et al., 2014; Falshaw et al., 2006; Ghobadian et al., 2008). By setting the objectives of a certain company, the various stages in SP will result in the effectiveness of the company and enhance the synchronization and control of its activities (McCarthy et al. (1996). So, the influence of the strategic plans impact on organizational commitment directly in terms of increase planning elements and increase the employee commitment in order to engage for long term success. The study findings was showed that strategic planning also significantly influence on university operational performance. Schwenk and Shrader, (1993) have shown that the relationship of this relationship in terms of performance which can proceed on operational and financial. Furthermore, the indirect influence on university operational performance, Miller and Cardinal, (1994) have explained that strategic leadership has influence on performance through organizational commitment. In this study, the performance has specified in university operational that makes different outputs for the findings rather than other studies.

Moreover, the significant influence of organizational commitmentand university operational performance comprises the relationship in order to increase employee committed loyalty of being with for long time. For instance, a committed member's definite desire to maintain organizational member-ship would have a clear relationship to the motivation to participate. Willingness to exert considerable effort on behalf of the organization and the belief in and acceptance of the organization's goals in combination have implications for the member's motivation to produce for the organization (Schwenk and Shrader, 1993). Moreover, organizational commitment significantly mediates between strategic planning and university operational performance.

Most importantly, the mediation effects of organizational commitment that is enrolled to maintain the commitment of the organization and the commitment of the employees. The findings were suggested that the mediation effect of organizational commitment placed as to provide the modification and motivation for the employees. Additionally, organizational commitment imply the employee participations in order to get innovative success by showing the performance (Schwenk and Shrader, 1993).

\section{IMPLICATIONS}

This study follows two of implications such as theoretical and managerial implications. The implications both are providedpossible suggestions in aspect of theories and practical. The theoretical implication of the study is to indicate the possible outcome which is retrieved from the relationship based findings. The findings of the present study establish condition to the effectiveness of strategic planning and university operational performance. Thus, the present study has confirmed the proposition of strategic planning on operational performance. Accordingly, relationship based outcomes consider the strategic planning influence on university operational performance within the organization. Arasa and K'Obonyo (2012) have argued that the primary goal of strategic planning is to guide the organization in setting out its strategic intent and priorities and refocus itself towards realizing the better performance. Poister (2010) have considered that strategic planning have associated with operational performance in terms of the organizational effectiveness. On the other hand, institutions of higher education are challenged by 
their constituents to operate responsibly. To a large extent, public trust regarding higher education is based on the expectation that institutions will follow sound administrative practices and consequently utilize available resources in the most efficient and effective manner (Buck and Watson, 2002). So that, the theories of these propositions od direct and indirect relationships judged, according to, the finding of the study.

Consequently, organizational commitment plays an important role as the mediator that shown as significant relationship with university operational performance. Universities are therefore forced to commit a substantial portion of their resources to replacement efforts and many of these resources are non-durable in nature, meaning once they are used they are gone forever. These precious resources can be better utilized in a different manner (Buck and Watson, 2002). Meanwhile, organizational commitment directly influence on university operational performance. The managerial implication indicates that organizations should not simply promote strategic plan to improve their sustainability and should take actions in order to better performance into account. Through, the higher education development programs could be made aware of the level of operational performance when more attention should be paid to stimulating organizational commitment or environment. It could be an important indication and findings for the universities to improve and develop further steps in order to follow the finding of this study.

\section{LIMITATION}

The current study has some limitations that offer an agenda for future research. As we confined ourselves to quantitative techniques, a large-scale follow-up survey would be useful to find out which of the identified organizational strategies to have the proposed connection with university operational performance. We found a wide range of strategic planning and operational performance that play a role but other university operational performance are most relevant is not yet clear. It seems unlikely that all practices can be treated as atomistic ingredients that have an additive enhancing effect on university operational performance. Also, in our survey we limited ourselves to leaders as a source of relevant approaches. Although some respondents were answered when they used to be an employee, additional respondents with other employees may provide a more comprehensive of relevant feedback.

\section{RECOMMENDATION}

Thus, future research should also try to address how strategies adapt to and even shape the environmental and organizational settings in such a way that the context optimally stimulates university operational performance. Furthermore, this was conducted in UAE context, for more clarification it may conduct in other geographical area which would be matched these theories.

\section{REFERENCES}

Abd-Elaziz, M.E., W.M. Aziz, G.S. Khalifa and M. Abdel-Aleem, 2015. Determinants of Electronic Word of Mouth (EWOM) influence on hotel customers purchasing decision. Intl. J. Heritage Tourism Hospitality, 9: 194-223.

Abou-Shouk, M.A. and G.S. Khalifa, 2017. The influence of website quality dimensions on E-purchasing behaviour and E-loyalty: A comparative study of Egyptian travel agents and hotels. J. Travel Tourism Marketing, 34: 608-623.

Ackfeldt, A.L. and N. Malhotra, 2013. Revisiting the role stress-commitment relationship: Can managerial interventions help?. Eur. J. Marketing., 47: 353-374.

Agwa, Y., W. Aziz and G. Khalifa, 2017a. Evaluating food and beverage courses in higher private tourism and hotels institutes in Alexandria: Professionals perception. Intl. J. Heritage Tourism Hospitality, 11: 98-110.

Agwa, Y., W. Aziz and G. Khalifa, 2017b. Evaluating food and beverage courses in higher private tourism and hotels institutes in Alexandria: Professionals perception. Intl. J. Heritage Tourism Hospitality, 11: 98-110.

Albacete-Saez, C.A., M.M. Fuentes-Fuentes and B.A. Maria, 2011. Quality management, strategic priorities and performance: The role of quality leadership. Ind. Manage. Data Syst., 111: 1173-1193.

Albadry, O.M., 2016. Strategic management and its impact on universities service quality: The role of organisational commitment. Masters Thesis, University Plymouth, Plymouth, UK.

Alfalla-Luque, R., J.A. Marin-Garcia and C. Medina-Lopez, 2015. An analysis of the direct and mediated effects of employee commitment and supply chain integration on organisational performance. Intl. J. Prod. Econ., 162: 242-257.

Alkhateri, A.S., A.E. Abuelhassan, G.S. Khalifa, M. Nusar and A. Ameen, 2018. The impact of perceived supervisor support on employees turnover intention: The mediating role of job satisfaction and affective organizational commitment. Intl. Bus. Manage., 12: 477-492.

Almatrooshi, B., S.K. Singh and S. Farouk, 2016. Determinants of organizational performance: A proposed framework. Intl. J. Productivity Perform. Manage., 65: 844-859. 
Arasa, R. and P. K'Obonyo, 2012. The relationship between strategic planning and firm performance. Intl. J. Hum. Soc. Sci., 2: 201-213.

Awang, Z., 2014. Structural Equation Modeling using AMOS. Penerbit Universiti Teknologi MARA, Shah Alam, Malaysia.

Ayers, R.S., 2015. Aligning individual and organizational performance: Goal alignment in federal government agency performance appraisal programs. Publ. Personnel Manage., 44: 169-191.

Babafemi, I.D., 2015. Corporate strategy, planning and performance evaluation: A survey of literature. J. Manage. Policies Pract., 3: 43-49.

Badran, N. and G. Khalifa, 2016. Diversity management: Is it an important issue in hotel industry in Egypt?. Intl. J. Heritage Tourism Hospitality, 7: 275-286.

Barclay, D., C. Higgins and R. Thompson, 1995. The Partial Least Squares (PLS) approach to causal modeling: Personal computer adoption and use as an illustration. Technol. Stud., 2: 285-309.

Basu, V., E. Hartono, A.L. Lederer and V. Sethi, 2002. The impact of organizational commitment, senior management involvement and team involvement on strategic information systems planning. Inform. Manage., 39: 513-524.

Baumruk, R., 2006. Why managers are crucial to increasing engagement: Identifying steps managers can take to engage their workforce. Strategic HR Rev., 5: 24-27.

Bergeron, F., L. Raymond and S. Rivard, 2004. Ideal patterns of strategic alignment and business performance. Inf. Manage., 41: 1003-1020.

Berry, B., 2016. The Power of Looks: Social Stratification of Physical Appearance. 1st Edn., Routledge, Abingdon, UK., ISBN:978-0-7546-4758-4, Pages: 142.

Bhatti, M.I., H.M. Awan and Z. Razaq, 2014. The Key Performance Indicators (KPIs) and their impact on overall organizational performance. Qual. Quantity, 48: 3127-3143.

Bowerman, B.L. and R.T. O'Connell, 1990. Linear Statistical Models: An Applied Approach. 2nd Edn., Duxbury Press, Grove, California, USA., ISBN:9780534229856, Pages: 1024.

Brynard, P. and S.X. Hanekom, 1997. Introduction to Research in Public Administration and Related Academic Disciplines. J.L. Van Schaik Academic, Amsterdam, Netherlands, ISBN:9780627022883, Pages: 76.

Bryson, J.M., 2010. The future of public and nonprofit strategic planning in the United States. Publ. Administration Rev., 70: 255-267.
Bryson, J.M., 2018. Strategic Planning for Public and Nonprofit Organizations: A Guide to Strengthening and Sustaining Organizational Achievement. 5th Edn., John Wiley \& Sons, Hoboken, New Jersey, USA., ISBN:9781119071600, Pages: 513.

Buck, J.M. and J.L. Watson, 2002. Retaining staff employees: The relationship between human resources management strategies and organizational commitment. Innovative Higher Educ., 26: 175-193.

Cardinal, L.B., C.C. Miller, M. Kreutzer and C. TenBrink, 2015. Strategic Planning and Firm Performance: Towards a Better Understanding of a Controversial Relationship. In: The Psychology of Planning in Organizations: Research and Applications, Mumford, M.D. and M. Frese (Eds.). Routledge, New York, USA., ISBN:978-1-138-80047-2, pp: 260-288.

Chin, W.W., 1998a. Commentary: Issues and opinion on structural equation modeling. MIS Q., 22: 7-16.

Chin, W.W., 1998b. The partial least squares approach to structural equation modeling. Modern Methods Bus. Res., 295: 295-336.

Cohen, J., 1988. Statistical Power Analysis for the Behavioral Sciences. 2nd Edn., Lawrence Erlbaum, Hillsdale, New Jersey, USA., ISBN: 0-8058-6283-5, Pages: 128.

Delpechitre, D., L.L. Beeler-Connelly and N. Chaker, 2018. Customer value co-creation behavior: A dyadic exploration of the influence of salesperson emotional intelligence on customer participation and citizenship behavior. J. Bus. Res., 92: 9-24.

Dembo, R., R. Briones-Robinson, K. Barrett, K.C. Winters and R. Ungaro et al., 2015. The validity of truant youths' marijuana use and its impact on alcohol use and sexual risk taking. J. Child Adolescent Substance Abuse, 24: 355-365.

Dhar, R.L., 2016. Ethical leadership and its impact on service innovative behavior: The role of LMX and job autonomy. Tourism Manage., 57: 139-148.

Dibrell, C., J.B. Craig and D.O. Neubaum, 2014. Linking the formal strategic planning process, planning flexibility and innovativeness to firm performance. J. Bus. Res., 67: 2000-2007.

Drucker, P.F. and S. Rousham, 1974. Effective management performance. Chartered Management Institute, London UK.

Falshaw, J.R., K.W. Glaister and T. Ekrem, 2006. Evidence on formal strategic planning and company performance. Manage. Decis., 44: 9-30.

Fornell, C. and D.F. Larcker, 1981. Evaluating structural equation models with unobservable variables and measurement error. J. Market. Res., 18: 39-50. 
Fornell, C. and J. Cha, 1994. Partial Least Squares. In: Advanced Methods in Marketing Research, Bagozzi, R.P. (Ed.). Blackwell,ý Oxfordý, England, UK., pp: 5278.

Galbreath, J., 2010. Drivers of corporate social responsibility: The role of formal strategic planning and firm culture. Br. J. Manage., 21: 511-525.

Garcia-Morales, V.J., M.M. Jimenez-Barrionuevo and L. Gutierrez-Gutierrez, 2012. Transformational leadership influence on organizational performance through organizational learning and innovation. J. Bus. Res., 65: 1040-1050.

Garg, S. and R.L. Dhar, 2014. Effects of stress, LMX and perceived organizational support on service quality: Mediating effects of organizational commitment. J. Hospitality, Tourism, Manage., 21: 64-75.

Gefen, D. and E.E. Rigdon, 2011. An update and extension to SEM guidelines for administrative and social science research. MIS. Q., 35: 1-7.

Gefen, D., D.W. Straub and M.C. Boudreau, 2000. Structural equation modeling and regression: Guidelines for research practice. Commun. Assoc. Inform. Syst., 4: 1-77.

Ghobadian, A., N. O'regan, H. Thomas and J. Liu, 2008. Formal strategic planning, operating environment, size, sector and performance: Evidence from the UKs manufacturing SMEs. J. Gen. Manage., 34: 1-20.

Gold, A.H., A. Malhotra and A.H. Segars, 2001. Knowledge management: An organizational capabilities perspective. J. Manage. Inform. Syst., 18: $185-214$

Haines, S., 2016. The Systems Thinking Approach to Strategic Planning and Management. 1st Edn., CRC Press, Boca Raton, Florida, USA., ISBN:9781420025699, Pages: 362.

Hair, Jr., J.F., G.T.M. Hult, C.M. Ringle and M. Sarstedt, 2017. A Primer on Partial Least Squares Structural Equation Modeling (PLS-SEM). 2nd Edn., Sage Publisher, Thousand Oaks, California.

Hair, Jr., J.F., W.C. Black, B.J. Babin and R.E. Anderson, 2010. Multivariate Data Analysis. 7th Edn., Prentice Hall, Upper Saddle River, NJ., ISBN-13: 9780138132637, Pages: 785.

Henseler, J., C.M. Ringle and M. Sarstedt, 2015. A new criterion for assessing discriminant validity in variance-based structural equation modeling. J. Acad. Marketing Sci., 43: 115-135.

Hussein, I.E., M.A. Abou-Shouk and G.S. Khalifa, 2013. Evaluating tourism and hospitality graduates: Perceptions of stakeholders in Egypt. Proceedings of the 3rd Regional Conference on Tourism Research, October 29-31, 2013, Bayview Hotel, Langkawi, Malaysia, pp: 764-774.
Jiang, B., G.V. Frazier and E.L. Prater, 2006. Outsourcing effects on firms operational performance: An empirical study. Intl. J. Oper. Prod. Manage., 26: 12801300 .

Joo, B.K. and J.H. Shim, 2010. Psychological empowerment and organizational commitment: The moderating effect of organizational learning culture. Hum. Resour. Dev. Intl., 13: 425-441.

Joyce, P., 2016. Strategic Leadership in the Public Sector. 2nd Edn., Routledge, Abingdon, UK., ISBN:978-1 138-95935-4, Pages: 344.

Kannan, V.R. and K.C. Tan, 2005. Just in time, total quality management and supply chain management: Understanding their linkages and impact on business performance. Omega, 33: 153-162.

Khalefa, G.S.A., 2015. Ethnic restaurants meal experience: Egyptian customers perceptions. Intl. J. Heritage Tourism Hospitality, 9: 92-112.

Khalifa, G.S. and E.H.M. Ali, 2017. Managing drivers and boundaries of Information Technology Risk Management (ITRM) to increase Egyptian hotels market share. Intl. J. Recent Trends Bus. Tourism, 1: $12-31$.

Khalifa, G.S. and M.A. Abou-Shouk, 2014. Investigating the success factors of hotel websites: The case of Egyptian hotels. Asia Pac. J. Innovation Hospitality Tourism, 3: 131-151.

Khalifa, G.S.A. and M. Hewedi, 2016. Factors affecting hotel website purchasing intentions: Evidence from Egypt. J. Faculty Tourism Hotels, Fayoum Univ., 8: 50-69.

Khalifa, G.S.A. and N.M. Fawzy, 2017. Measuring Eservice quality (Expectation vs. perception) from travel agencies perspective: An empirical study on egyptian hotel websites. Intl. J. Recent Trends Bus. Tourism (IJRTBT), 1: 36-48.

Kline, R.B., 2010. Principles and Practice of Structural Equation Modeling. 3rd Edn., The Guilford Press, New York, USA., ISBN-13: 9781606238769 , Pages: 427.

Kohtamaki, M., S. Kraus, M. Makela and M. Ronkko, 2012. The role of personnel commitment to strategy implementation and organisational learning within the relationship between strategic planning and company performance. Int. J. Entrepreneurial Behav. Res., 18: 159-178.

Marshall, C. and G.B. Rossman, 1999. Designing Qualitative Research. 5th Edn., Sage Publications, California, USA., ISBN:9780761913405, Pages: 224.

McAfee, R.B. and P.J. Champagne, 1993. Performance management: A strategy for improving employee performance and productivity. J. Manage. Psychol., 8: $24-32$ 
McCarthy, D., R. Minichiello and J. Curran, 1996. Business Policy and Strategy: Concepts and Readings. 4th Edn., AITBS Publishers Inc, Delhi, India, ISBN:9788185386492, Pages: 544.

Meyer, J.P. and N.J. Allen, 1984. Testing the side-bet theory of organizational commitment: Some methodological considerations. J. Appl. Psychol., 69: 372-378.

Meyer, J.P., V. Paunon, I.R. Gellatly, R.D. Goffin and D.N. Jackson, 1989. Organizational commitment and job performance. J. Applied Psychol., 74: 152-156.

Miller, B.A., 2016. Assessing Organizational Performance in Higher Education. John Wiley \& Sons, Hoboken, New Jersey, USA., ISBN-13:978-0-7879-8640-7.

Miller, C.C. and L.B. Cardinal, 1994. Strategic planning and firm performance a synthesis of more than two decades or research. Acad. Manage. J., 37: 1649-1665.

Mintzberg, H., 2000. The Rise and Fall of Strategic Planning. Prentice Hall, New Jersey, USA., ISBN:9780273650379, Pages: 458.

Mohamed, M.S., G.S.A. Khalifa, M. Nusari, A. Ameen and A.H. Al-Shibami et al., 2018. Effect of organizational excellence and employee performance on organizational productivity within healthcare sector in the UAE. J. Eng. Appl. Sci., 13: 6199-6210.

Mohamud, S.S., G.S.A. Khalifa, A.E. Abuelhassan and S. Kaliyamoorthy, 2017. Investigating the antecedents of coffee shop customers' behavioral intentions in Kuala Lumpur. Intl. J. Recent Trends Bus. Tourism, 1: $1-14$.

Morsy, M.A., G.S. Ahmed and N.A.A. Ali, 2016. Impact of effective training on employee performance in hotel establishments. Intl. J. Heritage Tourism Hospitality, 10: 92-109.

Mosadeghrad, A.M. and M. Ferdosi, 2013. Leadership, job satisfaction and organizational commitment in healthcare sector: Proposing and testing a model. Mater. Socio Med., 25: 121-126.

Mowday, R.T., R.M. Steers and L.W. Porter, 1979. The measurement of organizational commitment. J. Vocat. Behav., 14: 224-247.

Murray, K.B. and J.B. Montanari, 1986. Strategic management of the socially responsible firm: Integrating management and marketing theory. Acad. Manage. Rev., 11: 815-827.

Myers, R.H., 1990. Classical and Modern Regression with Applications. 2nd Edn., Duxbury, Washington.

Nusari, M., M. Al Falasi, I. Alrajawy, G.S. Khalifa and O. Isaac, 2018. The impact of project management assets and organizational culture on employee performance. Intl. J. Manage. Hum. Sci., 2: 15-26.
O'Brien, R.M., 2007. A caution regarding rules of thumb for variance inflation factors. Qual. Quantity, 41: 673690 .

Ouakouak, M.L. and N. Ouedraogo, 2013. The mediating role of employee strategic alignment in the relationship between rational strategic planning and firm performance: A European study. Can. J. Administrative Sci. Rev. Canadienne Sci. Administration, 30: 143-158.

Poister, T.H., 2010. The future of strategic planning in the public sector: Linking strategic management and performance. Public Administration Rev., 70: 246-254.

Poister, T.H., D.W. Pitts and L.H. Edwards, 2010. Strategic management research in the public sector: A review, synthesis and future directions. Am. Rev. Public Administration, 40: 522-545.

Preacher, K.J. and A.F. Hayes, 2008. Asymptotic and resampling strategies for assessing and comparing indirect effects in multiple mediator models. Behav. Res. Methods, 40: 879-891.

Qoura, O. and G.S.A. Khalifa, 2016. The impact of reputation management on hotel image among internal customers: The case of egyptian hotels. Intl. J. Heritage Tourism Hospitality, 7: 261-274.

Ringle, C.M. and M. Sarstedt, 2016. Gain more insight from your PLS-SEM results: The importanceperformance map analysis. Ind. Manage. Data Syst., 116: $1865-1886$.

Roast, S. and N. Silva-Rojas, 2007. Internal branding: development of brand values and organizational commitment. Masters Thesis, Lulea University of Technology, Lulea, Sweden.

Rolstadas, A., 1998. Enterprise performance measurement. Intl. J. Oper. Prod. Manage., 18: 989-999.

Schumacker, R.E. and R.G. Lomax, 2004. A Beginner's Guide to Structural Equation Modeling. 2nd Edn., Lawrence Erlbaum, New York, USA.

Schwartz, M.S., 2017. Corporate Social Responsibility. 1st Edn., Routledge, Abingdon, UK., ISBN: 9781351948418, Pages: 560.

Schwenk, C.R. and C.B. Shrader, 1993. Effects of formal strategic planning on financial performance in small firms: A meta-analysis. Entrepreneurship Theory Pract., 17: 53-64.

Shamsi, R.S.H.A., A.A. Ameen, O. Isaac, A.H. Al-Shibami and G.S. Khalifa, 2018. The impact of innovation and smart government on happiness: Proposing conceptual framework. Intl. J. Manage. Hum. Sci., 2: $10-26$. 
Siren, C. and M. Kohtamaki, 2016. Stretching strategic learning to the limit: The interaction between strategic planning and learning. J. Bus. Res., 69: 653-663.

Siren, C.A., M. Kohtamaki and A. Kuckertz, 2012. Exploration and exploitation strategies, profit performance and the mediating role of strategic learning: Escaping the exploitation trap. Strategic Entrepreneurship J., 6: 18-41.

Sullivan, G.M. and R. Feinn, 2012. Using effect size-or why the $\mathrm{P}$ value is not enough. J. Graduate Med. Educ., 4: 279-282.

Tangen, S., 2003. An overview of frequently used performance measures. Work Study, 52: 347-354.

Tonnessen, T. and T. Gjefsen, 1999. The enterprise development: Direct employee participation in strategic planning. Total Qual. Manage., 10: 739-744.

Van der Bij, H., X.M. Song and M. Weggeman, 2003. An empirical investigation into the antecedents of knowledge dissemination at the strategic business unit level. J. Prod. Innovation Manage., 20: 163-179.
Waddock, S. and C. Bodwell, 2017. Total Responsibility Management: The Manual. Taylor \& Francis, Abingdon, UK., ISBN:9781351280389, Pages: 192.

Werts, C.E., R.L. Linn and K.G. Joreskog, 1974. Intraclass reliability estimates: Testing structural assumptions. Educ. Psychol. Meas., 34: 25-33.

Wilden, R., Gudergan, S.P., B.B. Nielsen and I. Lings, 2013. Dynamic capabilities and performance: strategy, structure and environment. Long Range Plann., 46: 72-96.

Wolf, C. and S.W. Floyd, 2017. Strategic planning research: Toward a theory-driven agenda. J. Manage., 43: 1754-1788.

Yousaf, Z. and A. Majid, 2016. Strategic performance through inter-firm networks: Strategic alignment and moderating role of environmental dynamism. World J. Entrepreneurship Manage. Sustainable Dev., 12: 282-298.

Zikmund, W., 2003. Exploring Marketing Research. 8th Edn., Thomson/South-Western, Ohio, USA., ISBN13: 9780324181487 , Pages: 744. 